\title{
Percepções dos Usuários de Crack sobre as suas Relações Familiares na Infância e Adolescência
}

\author{
Naiara Alves de Barros $^{1} \&$ Adriana Marcassa Tucci ${ }^{1, *}$ \\ ${ }^{1}$ Departamento de Saúde, Educação e Sociedade, Universidade Federal de São Paulo, São Paulo, SP, Brasil
}

\begin{abstract}
RESUMO - O objetivo principal deste estudo foi compreender a percepção dos usuários de crack sobre suas famílias de origem durante a infância e a adolescência. Realizou-se uma pesquisa qualitativa, da qual participaram 29 usuários de crack de ambos os sexos. Os dados oriundos das entrevistas semiestruturadas foram analisados de acordo com o conteúdo temático e organizados em categorias. Os resultados revelaram que os usuários de crack percebem os vínculos familiares como frágeis. Além disso, mencionaram a vivência de situações de violência e consumo de drogas entre os membros da família. Os dados indicam a necessidade de cuidado dos familiares, os quais, muitas vezes, também enfrentam problemas com o uso de substâncias, e o desenvolvimento de ações educativas preventivas na infância e na adolescência.
\end{abstract}

PALAVRAS-CHAVE: relações familiares, cocaína, crack, adolescência

\section{Perceptions of Crack Users on their Family Relationships in Childhood and Adolescence.}

\begin{abstract}
The main objective of this study was to analyze the perceptions of crack users on their family relationships in childhood and adolescence. In this qualitative study, 29 crack users of both sexes participated. Data from the semistructured interviews were analyzed according to thematic content and organized into categories. Results show that the crack users perceive their family bonds during childhood and adolescence as fragile. In addition, they mention the experience of violence and drug use among family members. The data indicate the need to strengthen the care of family members, who often also face problems related to substance use, and the development of preventive educational activities in childhood and adolescence.

KEYWORDS: family relations, crack, cocaine, adolescence
\end{abstract}

O consumo de drogas, atualmente, é considerado uma questão de saúde pública devido aos agravos à saúde dos usuários bem como aos problemas sociais e coletivos decorrentes do uso nocivo de drogas. Especificamente em relação ao consumo de crack, sabe-se que pode ocasionar insônia, depressão, diminuição do apetite, aumento da frequência cardíaca e da pressão arterial, problemas respiratórios e neurológicos (Bordin et al., 2010; Cruz et al., 2011). Verificam-se também, com certa frequência, danos sociais e familiares, pois geralmente o usuário de crack vende os próprios pertences ou dos familiares, envolve-se em atividades ilícitas como furtos, tráfico de drogas e prostituição para conseguir comprar a droga, expondo-se a situações de risco, tais como violência, homicídio, transmissão de doenças infectocontagiosas e gravidez indesejada (Nappo et al., 2004; Oliveira \& Nappo, 2008; Ribeiro et al., 2010). Além disso, o usuário de crack vem sendo associado pela mídia à criminalidade e à marginalidade, representando uma posição diferenciada em relação às outras drogas (Rodrigues, Conceição, \& Lunes, 2015; Albuquerque, 2010).

Os levantamentos domiciliares nacionais realizados pelo Centro Brasileiro de Informações sobre Drogas Psicotrópicas (CEBRID) em 2001 e 2005 evidenciaram que o uso de crack ao longo da vida aumentou de $0,4 \%$ em 2001 para $0,7 \%$ em 2005 (Carlini et al., 2002, 2006). Dados do II Levantamento Nacional de Álcool e Drogas (LENAD) demonstram que aproximadamente dois milhões de brasileiros já usaram cocaína fumada (crack/merla e oxi) pelo menos uma vez na vida (Laranjeira et al., 2012). Segundo os dados da United

\footnotetext{
*E-mail: atucci@unifesp.br
} 
Nations Office on Drug and Crime (UNODC, 2010, 2014), o Brasil encontra-se em segundo lugar em número absoluto de consumidores de cocaína no mundo, atrás apenas dos Estados Unidos da América. Assim, no Brasil, o consumo de cracks se tornou uma problemática que atingiu dimensões preocupantes na atualidade, podendo trazer danos ao usuário, à família e à sociedade (Raupp \& Adorno, 2011; Seleghim et al., 2011), chamando a atenção governamental para os usuários dessa substância.

Em 2010, por meio do decreto 7.179, foi instituído o Plano Integrado de Enfrentamento ao Crack e outras Drogas (PIEC; Brasil, 2010), com o intuito de se desenvolver um conjunto integrado de ações de prevenção, tratamento e reinserção social, incluindo a participação dos familiares. Assim, o consumo de crack colocou em pauta o tema "drogas" na agenda das políticas públicas.

No Brasil, nos últimos anos, verifica-se uma expansão de estudos envolvendo os usuários de crack (Albuquerque, 2010; Bastos \& Bertoni, 2014; Chaves et al., 2011; Schaurich et al., 2012). Em 2014, foram divulgados os resultados da maior pesquisa nacional que estudou o perfil dos usuários dessa substância. Tal estudo foi realizado nos locais públicos/ abertos onde ocorre o consumo e foi observado que o uso de crack é mais frequente do que o consumo de similares à cocaína. O perfil dos usuários identificados é, na sua maioria, constituído por homens, jovens, solteiros, com baixa escolaridade, vivendo em situação de rua e desempregados, revelando-se como um grupo socialmente vulnerável (Bastos $\&$ Bertoni, 2014). Tal perfil já havia sido citado em estudos nacionais realizados anteriormente (Gabatz et al., 2013; Laranjeira et al., 2012; Oliveira \& Nappo, 2008b). Entre os principais motivos para o primeiro uso do crack, $29,2 \%$ dos entrevistados mencionam a presença de problemas familiares ou perdas afetivas (Bastos \& Bertoni, 2014). Além disso, os usuários de cocaína/crack apresentam mais problemas no relacionamento familiar quando comparados aos usuários de outras drogas (Moura et al., 2014).

Embora seja notório o aumento de estudos sobre o crack no Brasil, existem ainda poucos estudos brasileiros que avaliaram a dinâmica e a composição familiar do usuário de crack (Schaurichet al., 2012; Seleghim, Galera, \& Oliveira, 2014; Seleghim et al., 2011). Seleghim et al. (2011) detectaram a existência de ruptura dos vínculos familiares e a presença de drogas e de violência no ambiente familiar de usuários de crack atendidos em uma unidade de emergência psiquiátrica. $\mathrm{O}$ estudo de revisão das teses e dissertações defendidas no Brasil, entre os anos de 1996 e 2008 que abordavam a temática sobre o crack revelou que, dos 33 trabalhos selecionados, a temática acerca da família foi citada somente em um estudo (Schaurich et al., 2012). Assim, acredita-se que o presente artigo possa acrescentar informações sobre as relações familiares e o uso de crack. Além disso, este estudo se diferencia da maioria dos estudos existentes no Brasil por analisar a percepção dos usuários de crack, valorizando, assim, o significado e a interpretação destes acerca da temática.
As relações familiares dos usuários de crack são importantes fontes a serem estudadas por transmitirem valores e modelos de comportamento, pois se sabe que indivíduos que presenciam a prática do uso de álcool ou drogas no ambiente familiar tendem a interpretar esse comportamento como comum, podendo reproduzi-lo mais facilmente (Roehrs, Lenardt, \& Maftum, 2008; Silva, 2011b; Souza, Amato, \& Sartes, 2013). Silveira e Silva (2013) indicam também que a família pode facilitar o início de uso de drogas na adolescência pelo fato de muitos pais acreditarem que drogas lícitas, como álcool e tabaco, não causam danos e acabarem não dialogando com os adolescentes sobre o assunto. Além disso, as autoras apontam outros fatores de risco presentes no ambiente familiar, tais como a ausência de vínculos familiares, monitoramento parental insuficiente, pais excessivamente autoritários ou muito exigentes, atitudes permissivas dos pais com relação ao uso de drogas e consumo abusivo de drogas pelos familiares.

No âmbito familiar, não se pode dizer que existe uma relação linear e causal entre o uso de drogas dos pais e de seus filhos, mas a presença dos fatores citados no parágrafo anterior pode influenciar as atitudes futuras dos filhos (Bernardy \& Oliveira, 2010; Moraes, Chalem, \& Figlie, 2010; Silveira \& Silva, 2013). Confirmando tais achados, Steiner, Schori e Gmel (2014) concluem que a influência dos pais em relação ao comportamento de beber álcool persiste até o início da vida adulta. No entanto, segundo a literatura, além dos aspectos familiares, existem diversos outros fatores que podem favorecer que um adolescente apresente maior ou menor risco para o uso de álcool ou outras drogas (Moraes et al., 2010; Payá \& Figlie, 2010). Conforme Payá e Figlie (2010), esses outros fatores seriam: a influência de amigos, a adesão ou não à escola e os aspectos psicológicos do indivíduo.

Os estudos sobre família no Brasil revelam a diversidade da sua organização e composição (Szymanski, 2002; Romanelli, 2003). Desse modo, não existiria um modelo único de família; ao contrário, cada uma apresenta seus valores, questões culturais, afetivas e trocas constantes com o meio social em que vive e que interfere nas suas relações (Silva, 2011a; Silveira \& Silva, 2013). Assim, no presente estudo, a família é entendida como um grupo no qual se estabelecem os vínculos de afeto e sentimento de pertencimento, e que possui importante papel na socialização, proteção e cuidado de seus membros, podendo contribuir para a prevenção do uso de drogas, assim como aumentar a vulnerabilidade frente às complexidades do tema.

Diante do exposto, verifica-se a relevância e a necessidade de melhor compreender a família no âmbito dos usuários de drogas, especialmente daqueles que fazem uso de crack. Portanto, este estudo tem como objetivo principal compreender a percepção dos usuários de crack sobre suas famílias de origem durante a infância e a adolescência. Além disso, pretende-se discutir as implicações desse contexto familiar no início e manutenção do uso de drogas. 


\section{MÉTODO}

O presente estudo foi conduzido a partir de metodologia qualitativa. Essa metodologia possibilita maior aproximação com os sujeitos entrevistados, permitindo conhecer as suas percepções, reconhecendo-os como protagonistas da pesquisa. Como consequência, facilita o processo de construção do conhecimento acerca de um determinado fenômeno investigado (Minayo, 2010).

\section{Participantes da Pesquisa}

Participaram deste estudo 29 usuários de crack de ambos os sexos. Os critérios de inclusão foram ter idade igual ou superior a 18 anos, ter feito uso de crack pelo menos 25 vezes na vida - evitando-se a inclusão de iniciantes - (Oliveira \& Nappo, 2008) e fazer uso da droga no município de Santos. Foram excluídos do estudo os participantes que estivessem, no momento da entrevista, sob o efeito da droga ou com sintomas de abstinência, o que impediria a realização da entrevista.

\section{Instrumento e Procedimento}

O instrumento utilizado na coleta de dados foi a entrevista semiestruturada (Turato, 2005). No entanto, foram acrescentadas algumas perguntas durante a entrevista conforme a necessidade ou pertinência do assunto (Minayo, 2010). As entrevistas tiveram duração média de 40 minutos e foram norteadas por um roteiro com questões acerca dos dados socioeconômicos e demográficos, relações familiares na infância, adolescência e na vida adulta, sendo que este artigo analisa os períodos da infância e da adolescência por se entender que, nesses períodos, a presença de fatores de risco no ambiente familiar pode favorecer o uso de drogas na vida adulta. As entrevistas foram gravadas, transcritas e cada uma recebeu, inicialmente, classificação alfa numérica (sexo, idade e iniciais do nome) e, posteriormente, foram identificadas por nomes fictícios para preservar a identidade dos entrevistados.

A pesquisa de campo foi realizada em um dos municípios da região metropolitana da Baixada Santista/SP. Os locais de coleta de dados foram uma instituição filantrópica que propicia assistência, cuidados e atividades que incentivam o lazer e reinserção social por meio de oficinas aos moradores de rua e pessoas em situação de vulnerabilidade $(\mathrm{N}=7)$; uma Comunidade Terapêutica da região, que se caracteriza por ser um centro de recuperação de dependentes de drogas, com sede administrativa em Santos $(\mathrm{N}=4)$; e locais públicos de cenas de uso de crack no referido município $(\mathrm{N}=18)$.
A inserção no campo de pesquisa foi mediada pelos dirigentes e profissionais das instituições (comunidade terapêutica e instituição filantrópica), assim como pelos próprios usuários de crack. Essa mediação facilitou o acesso e o contato com os usuários entrevistados, além de possibilitar maior aproximação com os usuários que se encontravam em situação de rua, população considerada de difícil acesso (Bastos \& Bertoni, 2014). Para a realização das entrevistas nas instituições, foi feito agendamento com a direção das mesmas, sendo que os entrevistados demonstraram grande interesse na participação do estudo. Tal fato possibilitou a detecção da necessidade desses usuários em serem ouvidos, o que contribuiu para que eles pudessem dar informações mais detalhadas sobre as relações familiares que eram pertinentes ao objetivo desta pesquisa.

No entanto, as entrevistas realizadas nas cenas de uso $(\mathrm{N}=18)$ dependeram de fenômenos climáticos, como a chuva, que, algumas vezes, impediu a ida a campo ou levou a entrevista a ser concluída mais rapidamente. Além disso, ocorreram intervenções da polícia que alteravam a dinâmica do campo de coleta de dados. Assim, nesse cenário, foi necessário encerrar a entrevista por razões como os usuários queriam fazer uso de crack; receio de que a polícia aparecesse no local ou desconfiança de que o traficante pudesse não gostar de sua participação na pesquisa. Tais situações conduziram à realização de entrevistas mais curtas, com informações mais objetivas quando comparadas com as entrevistas realizadas dentro das instituições.

Os usuários de crack interessados em participar da pesquisa foram esclarecidos pela pesquisadora sobre os seus propósitos e sobre os aspectos éticos envolvidos para assinarem o Termo de Consentimento Livre e Esclarecido. O presente estudo foi submetido e aprovado pelo Comitê de Ética em Pesquisa da Universidade Federal de São Paulo (parecer CEP ${ }^{\circ} 758.214$ ).

\section{Análise de Dados}

As entrevistas semiestruturadas foram submetidas à análise temática de conteúdo, considerando os seguintes procedimentos: leitura exaustiva de cada entrevista; estabelecimento de categorias temáticas; organização e análise do material, segundo as categorias temáticas; e cotejamento dos conteúdos das categorias com a literatura existente sobre a temática e com as referências teóricas que nortearam a pesquisa (Minayo, 2010). Os temas das entrevistas foram explorados até o momento em que as informações passaram a se repetir e o ponto de saturação teórica foi atingido (Minayo, 2010; Oliveira \& Nappo, 2008; Ribeiro, Sanchez, \& Nappo, 2010). 


\section{RESULTADOS}

A caracterização dos entrevistados, apresentada na Tabela 1, é constituída por nome fictício, idade, escolaridade, estado civil, condições de trabalho, início do uso de drogas, condições de moradia e contato com a família. A maioria dos entrevistados deste estudo é do sexo masculino $(\mathrm{N}=18)$, com idade variando de 18 - 52 anos, com trabalho informal $(\mathrm{N}=17)$, sendo que as atividades mais frequentemente mencionadas foram a coleta de material reciclável $(\mathrm{N}=6)$ e "cuidar" dos carros estacionados na rua $(\mathrm{N}=5)$. Os estados civis separado $(\mathrm{N}=12)$ e solteiro $(\mathrm{N}=9)$ foram os mais reportados. A escolaridade variou de analfabeto $(\mathrm{N}$ $=02)$ a ensino superior incompleto $(\mathrm{N}=02)$, sendo que o ensino fundamental foi a escolaridade cursada com maior frequência $(\mathrm{N}=13)$. Em relação às condições de moradia, a maioria estava em situação de rua $(\mathrm{N}=18)$ e esses foram os sujeitos que foram entrevistados nas cenas de uso de crack. Entretanto, mais da metade mencionou que ainda mantinha contato com algum parente próximo, assim o vínculo familiar não estava totalmente rompido para a maioria desses usuários $(\mathrm{N}=23)$.

Tabela 1 Caracterização dos Aspectos Socioeconômicos e Demográficos dos Participantes da Pesquisa

\begin{tabular}{|c|c|c|c|c|c|c|c|}
\hline Nome fictício & $\begin{array}{l}\text { Idade } \\
\text { (anos) }\end{array}$ & Escolaridade & Estado civil & Trabalho & $\begin{array}{l}\text { Início do uso } \\
\text { de drogas }\end{array}$ & Moradia atual & $\begin{array}{l}\text { Contato com } \\
\text { a família }\end{array}$ \\
\hline Alex & 26 & Médio incompleto & Solteiro & Bico & 9 anos Maconha & Rua & Mãe \\
\hline Lucas & 51 & Não consta & Separado & Desempregado & 21 anos Maconha & C.T & Não \\
\hline Paulo & 38 & Ensino médio completo & Separado & Desempregado & 13 anos Maconha & Rua & Tias \\
\hline Humberto & 36 & $\begin{array}{l}\text { Fundamental } \\
\text { incompleto }\end{array}$ & Separado & Desempregado & 13 anos Álcool & C.T & Irmãos \\
\hline Aline & 27 & Ensino médio completo & Separada & Bico & 9 anos Cigarro & Rua & Mãe \\
\hline Pedro & 30 & $\begin{array}{l}\text { Fundamental } \\
\text { incompleto }\end{array}$ & Solteiro & Desempregado & 10 anos Maconha & Rua & Tia \\
\hline João & 43 & Ensino fundamental & Solteiro & Bico & 7 anos Cigarro & Rua & Filhos \\
\hline Luis & 31 & Não consta & Separado & Desempregado & 14 anos Maconha & Casa & Mãe / irmão \\
\hline Andreia & 29 & Médio incompleto & Solteira & Bico & 13 anos Maconha & Rua & Filho \\
\hline Bianca & 31 & Analfabeta & Casada & Bico & 23 anos Álcool & Rua & Filho/ marido \\
\hline Alberto & 30 & Ensino médio completo & Separado & Bico & 16 anos Cocaína & Rua & Mãe \\
\hline Lais & 19 & $\begin{array}{l}\text { Fundamental } \\
\text { incompleto }\end{array}$ & Solteira & Bico & 11 anos Maconha & Rua & Padrasto \\
\hline Viviane & 27 & Ensino fundamental & Casada & Bico & 11 anos Cigarro & Rua & Marido \\
\hline Igor & 28 & $\begin{array}{l}\text { Fundamental } \\
\text { incompleto }\end{array}$ & Separado & Bico & 9 anos Álcool & Rua & Mãe do filho \\
\hline Vanessa & 29 & Ensino fundamental & Casado & Desempregada & 12 anos Cigarro & Rua & Pai/filho/marido \\
\hline Jair & 52 & Ensino Médio completo & Separado & Desempregado & 18 anos Maconha & C.T & Filhos \\
\hline Fabio & 18 & $\begin{array}{l}\text { Fundamental } \\
\text { incompleto }\end{array}$ & Casado & Bico & 10 anos Cigarro & Casa & Namorada \\
\hline Monica & 38 & Superior incompleto & Solteira & Bico & 9 anos Maconha & Não consta & Não consta \\
\hline Marcio & 22 & $\begin{array}{l}\text { Fundamental } \\
\text { incompleto }\end{array}$ & Separado & Desempregado & 14 anos Maconha & Rua & Mãe \\
\hline Mario & 28 & $\begin{array}{l}\text { Fundamental } \\
\text { incompleto }\end{array}$ & Solteiro & Bico & 12 anos Cigarro & Rua & Mãe \\
\hline Milene & 28 & Semi- analfabeta & Separada & Desempregada & 12 anos Maconha & Não consta & Não consta \\
\hline Ricardo & 26 & Médio incompleto & Casado & Desempregado & 16 anos Cocaína & C.T & Filhos \\
\hline Roger & 36 & $\begin{array}{l}\text { Fundamental } \\
\text { incompleto }\end{array}$ & Solteiro & Desempregado & 14 anos Maconha & C.T & Não \\
\hline Hugo & 30 & Ensino médio completo & Separado & Bico & 10 anos Maconha & Não consta & Pais \\
\hline Ana & 19 & $\begin{array}{l}\text { Fundamental } \\
\text { incompleto }\end{array}$ & Casada & Bico & 10 anos Maconha & Rua & Marido/irmã \\
\hline Nair & 26 & Médio incompleto & Casada & Bico & 17 anos Crack & Rua & Não \\
\hline Naldo & 23 & Médio incompleto & Solteiro & Bico & 12 anos Maconha & Rua & Filho \\
\hline Gabriel & 25 & Médio incompleto & Separado & Desempregado & 10 anos Maconha & Rua & Não consta \\
\hline Neusa & 37 & Ensino fundamental & Casada & Bico & 15 anos Maconha & Casa & Marido \\
\hline
\end{tabular}

Fonte: informações obtidas das entrevistas. C.T = Comunidade Terapêtica 
Considerando que a finalidade do estudo foi compreender a percepção dos usuários de crack sobre suas famílias de origem durante a infância e a adolescência e discutir as implicações desse contexto familiar no início e manutenção do uso de drogas, os resultados do estudo foram organizados em três categorias: 1) composição e dinâmica de relacionamento na família de origem; na infância e adolescência; 2) situações de violência na infância e adolescência; 3) histórico familiar de uso de álcool ou outras drogas e as implicações desse uso no contexto familiar.

\section{Composição e Dinâmica de Relacionamento na Família de Origem}

Esta categoria apresenta a composição e dinâmica familiar a partir da percepção dos usuários de crack e do relacionamento vivido com os familiares na infância e na adolescência.

$\mathrm{Na}$ infância, a convivência familiar foi estabelecida a partir de diversas composições do núcleo familiar. Aline (27 anos) disse: "eu sou adotada, a minha mãe verdadeira não é do Brasil, ela é da Espanha e eu fui adotada por um casal de brasileiros". Por outro lado, Mario (28 anos) contou " $L a ́$ em casa eram 25 pessoas na minha casa (...). Meus pais, irmãos, avós, tios e tias, neto e primos". Hugo (30 anos) relatou que sua família era: "pai, mãe e (...) seis irmãos". Alberto (30 anos) também disse: "Eu sou o mais novo de 6 irmãos, (morava) com meu pai e minha mãe. Naldo (23 anos) contou "Meu pai morreu quando eu tinha um ano de idade. Eu não conheci o meu pai. (Criado) Só pela minha mãe. Neusa (37 anos) falou: "Eu tenho três irmãos, uma irmã e dois irmãos. (Morava) com minha mãe". Dessa maneira, não foi identificado um tipo específico de composição da família de origem.

Em relação à dinâmica familiar, durante a fase da infância e da adolescência, foram identificados conflitos, sentimentos de rejeição, abandono e perdas afetivas, sendo que, dentre os motivos apontados pelos entrevistados para a existência de tais sentimentos e situações estiveram presentes a separação dos pais e dificuldades financeiras, conforme as falas a seguir: Vanessa (29 anos): "Com 7 anos, o meu pai abandonou minha mãe e aí começaram as dificuldades financeiras, que a minha mãe sozinha não tava conseguindo bancar todos os luxos, tanto os nossos como os dela". Gabriel (25 anos) contou: "Minha mãe nunca fez um bolo (aniversário). Dificuldade né? A gente ficava sem dinheiro, só meu pai que trabalhava. (Depois) Meu pai, ele faleceu. Bianca (31 anos): "Eu tinha o meu pai, mas praticamente eu não gostava dele, por causa que ele me deu para uma família, ele tinha a mulher dele e não quis me criar, entendeu? Aí eu e meu pai não se dá, até hoje".

O entrevistado Alex (26 anos) revelou os seus sentimentos em relação ao pai que não assumiu a paternidade: "Meu pai primeiramente, não sei nem como era a face dele, foi um pilantra, largou minha mãe com dois filhos pequenos $e$ grávida de mim de 3 meses".

Assim, pode-se perceber que os resultados apresentados revelam haver uma diversidade na composição familiar. Além disso, a dinâmica familiar detectada nos relatos dos usuários mostra a presença de sentimentos de rejeição e abandono, assim como a ausência da figura paterna.

\section{Situações de Violência na Infância e Adolescência}

Esta categoria identifica diferentes tipos de violência a que os participantes foram submetidos na infância e na adolescência pelos seus familiares. Revela também sua percepção sobre a violência sofrida.

A maioria dos entrevistados mencionou a presença frequente de algum tipo de violência no contexto familiar de origem. Vanessa (29 anos) contou que o padrasto tentou violentá-la sexualmente: "Tentou abusar de mim. Eu com 11, 12 anos ele me acordava, alisando as minhas partes íntimas. Eu falava pra minha mãe, minha mãe achava que era invenção minha porque eu queria afastar ela dele". Embora tenham ocorrido citações de violência sexual e psicológica, a violência física foi a mais mencionada pelos entrevistados. Conforme afirmações a seguir: Viviane (27 anos): "Eu fui judiada muito pela minha avó (...). Minha mãe me batia muito. Minha avó também, tenho marcas no corpo inteiro (...) de tanto apanhar ". Bianca (31 anos): "Apanhava, apanhava de relho. Ah! Foi a maneira deles ter criado nós. Foi embaixo de cacete mesmo." O entrevistado Paulo (38 anos) disse: "Era surra mesmo, tirava o fio do ferro e me surravam. Hoje eu vejo e tento compreender que a forma deles querer o melhor, querer o bem pra mim, querer me educar, era aquela forma ignorante de me agredir, de me bater".

Nesse sentido, alguns entrevistados afirmaram que a violência era utilizada como uma forma de "correção" e de "educar", conforme Igor (28 anos) mencionou: "Minha mãe me batia muito (...)". Ah! Pegava aquelas varinhas de goiaba e dava umas 3, 4, não aquela surra, pra corrigir os erros né?". Outro entrevistado mencionou que apanhava, pois a mãe queria que ele estudasse: "Eu cabulava escola para ir para o laguinho perto de casa .E ai quando minha mãe descobria, ela me batia, me batia muito, mas era por causa da escola, ela queria que eu estudasse, queria que eu fosse alguém na vida" (Naldo, 23 anos).

Nesta categoria, foi possível perceber que os entrevistados sofreram diferentes formas de violência na infância e na adolescência. As falas e comportamentos violentos praticados pelos familiares eram percebidos pelos os usuários como uma maneira de se educar e corrigir os erros. Os dados revelaram que a violência era uma prática comum nas relações familiares. 


\section{Histórico Familiar de Uso de Álcool ou Outras Drogas e as Implicações desse Uso no Contexto Familiar}

Esta categoria aponta o histórico de uso de álcool ou outras drogas no âmbito familiar, bem como problematiza os fatores de risco presentes no contexto familiar que podem influenciar o início de uso de drogas na infância ou na adolescência.

Verificou-se nos relatos a presença frequente de histórico familiar com uso de álcool ou outras drogas. Vanessa (29 anos) contou: "A minha mãe, ela é alcoólatra". Mônica (38 anos) mencionou: "Meu pai bebia demasiadamente, bebia duas garrafas de Dreher por dia, ele era dono de bar (...)". Humberto (36 anos) disse: "Meu avô, meus tios quase a maioria toda, tem um tio que é alcoólatra”. Luis (31 anos) falou: "O meu pai bebia (...). Eu sempre passava por várias dificuldades em ver ele bêbado”. Lais (19 anos) também revelou a presença do consumo de drogas no ambiente familiar: "Minha mãe morreu (com) 40 anos (...) minha mãe bebia muito. Meus irmãos, um fumava maconha, outro crack".

Pôde-se notar também que o uso de crack foi mencionado pelos usuários como sendo uma prática presente entre os familiares. Ana (19 anos) mencionou: “(...) minha mãe já era viciada também (usava) crack, sempre (...) ia muita gente em casa para usar a droga, muita, muita e ela (mãe) não usava, ela começou a acabar usando, vendendo, aí ficou um bom tempo assim". Milene (28 anos) falou: "E ele (pai) usava droga. Ele usava crack. (Também) Usa, mais dois irmãos". Andreia (29 anos) afirmou: "Eu já vi minha mãe usando droga (crack)". Lucas (51 anos) disse: "Eu tenho um irmão, esse morreu. Ele que me apresentou o crack".

Uma das possíveis consequências da presença do uso de álcool ou outras drogas no ambiente familiar pode ter sido o início precoce do uso dessas substâncias relatado pelos entrevistados, pois a maioria mencionou ter feito o primeiro uso na infância ou no início da adolescência. Mario (28 anos) contou: "Primeiro foi o cigarro (...) aos 12 anos. Depois (...) bebida alcoólica, já tinha meus 13, depois maconha, depois o crack e a cocaina. Na adolescência, é que comecei a usar crack, maior vacilo". Fabio (18 anos) disse: "Com 10 anos comecei a fumar cigarro, com 13 anos comecei a usar cocaina, mesclado e tomar bola".

Além do início precoce do uso de drogas, foi identificado nos relatos que o uso de drogas na infância ou na adolescência ocorria com o consentimento ou mesmo com o compartilhamento do uso com os pais. Igor (28 anos) disse: "Eu ficava até mais tarde com meu pai no bar e foi quando ele me oferecia um golinho de cerveja, eu bebia quando eu era moleque (...) com nove anos eu já experimentava”. Já Márcio (22 anos) relatou:

Meu pai e minha mãe sempre foram usuários de crack, eu conheci o crack da mão deles. (Tinha) 17 anos... Estava chegando de uma festa e eu dava dinheiro porque meu pai tinha um corre de pó bom (cocaína). É, eu dava dinheiro para ele trazer e neste dia ele não trouxe o pó, cheguei em casa ele estava fumando (crack), fiquei bravo, furioso (...) ai ele estava fumando, e eu falei: Já que você não trouxe o pó, deixa eu fumar esta porra ai, fumei (crack) e acabou.

Entre as implicações geradas pelo uso de álcool ou outras drogas no âmbito familiar, destacou-se a presença de comportamento violento, de brigas e de separações entre os pais. Algumas destas foram apresentadas na categoria anterior e, apesar de fazerem parte do mesmo contexto e estarem intrinsicamente associadas, optou-se pelo desmembramento em duas categorias, pois na categoria anterior o enfoque estava no participante enquanto vítima direta dos comportamentos de violência física ou sexual e nesta, a violência se apresentou como consequência do uso abusivo de álcool ou outras drogas, sendo a vítima, na maioria das situações, as mães.

Nas situações mencionadas pelos entrevistados, o agressor geralmente era o pai, o qual se encontrava sob o efeito de drogas e apresentava atitudes que ocasionavam brigas, discussões e agressões físicas. Entre as falas, João (43 anos) disse: "O meu pai era alcoólatra, ele chegava em casa querendo quebrar as coisas, de vez em quando a gente brigava". Marcio (22 anos) mencionou a respeito da violência física: "Já, via lá em casa mesmo, meu pai sempre batendo na minha mãe. Assistíamos e também participávamos" [Não dava denuncia?] "Мeu pai na época, como ele vendia droga, era assaltante, então (...) todo mundo respeitava, ficava com medo, então ninguém se envolvia.

Durante essas brigas, os filhos se envolviam para proteger a mãe:

Chegamos a sair na porrada mesmo, teve uma vez que eu cheguei a falar para ele: Você quer conversar comigo? Você só conversa comigo quando você estiver são, eu vou te escutar, porque se você voltar bêbado pra casa, você vai querer brigar com a minha mãe, você vai querer agredir minha mãe e depois querer vir pra cima de mim, não vai dar certo, foi o quê aconteceu, ai eu fiquei um bom tempo sem se falar, isto que eu estou falando já foi com os meus dezesseis. (Ricardo, 26 anos)

Outra possível consequência do uso de drogas foi a separação dos pais. Ricardo (26 anos) acrescentou “(...) eu e minha mãe tomamos a decisão de sair de casa (...), a gente saiu e foi morar com a minha tia". Milene (28 anos) disse: "meu pai e minha mãe brigavam muito. Eles se separavam direto (...) É, mas não por causa da minha mãe, é culpa do meu pai (...) ele usava drogas. Ademais, foi mencionada morte devido ao uso de álcool. Roger (36 anos) contou "Que aconteceu, com o tempo meu pai morreu devido à bebida".

Nesta categoria, foram identificados alguns fatores de risco para o uso de álcool ou outras drogas, como o uso de crack entre os familiares, o uso compartilhado dos pais com 
os filhos e a violência no ambiente familiar desencadeada pelo uso das drogas. As implicações desses fatores parecem ter contribuído para o início precoce do uso de drogas entre os entrevistados, separação entre os pais e morte devido a problemas com o uso de drogas.

\section{DISCUSSÃO}

O presente artigo traz contribuições relevantes acerca da temática do crack e das relações familiares. Diferencia-se da maioria dos estudos existentes no Brasil por analisar a percepção dos usuários de crack, valorizando, assim, o significado que atribuem às experiências vividas na infância e na adolescência com sua família de origem.

A partir dos resultados deste estudo, identificou-se a diversidade da composição familiar na infância dos usuários. Tal dado difere da literatura, cujos estudos apontam que a composição familiar da maioria dos usuários de álcool e outras drogas é constituída por família monoparental (Laranjeira et al., 2013; Seleghim \& Oliveira, 2013; Hemovich \& Crano, 2009). A literatura aponta que as famílias monoparentais, devido à ausência paterna ou materna, geralmente, possuem menos recursos financeiros e os filhos recebem um monitoramento menos intenso e menos consistente (Hemovich \& Crano, 2009; Seleghim \& Oliveira, 2013) e, por essas razões, poderiam favorecer o uso de drogas pela criança ou adolescente. Narvaez et al. (2015) identificaram alta frequência de ausência paterna no ambiente domiciliar, sugerindo que esse contexto pode repercutir no suporte parental mais negligente e imprudente pela presença apenas da mãe como figura educadora. Corroborando esses dados, Pettenon et al. (2014) mostraram que os usuários de crack têm uma percepção da figura materna como negligente e da paterna como controladora e sem afeto.

No entanto, as entrevistas do presente estudo sugerem não haver uma relação direta entre a composição familiar e o consumo de drogas, revelando a presença de alguns outros fatores relevantes na dinâmica familiar e que são também mencionados na literatura, tais como a presença de perdas afetivas significativas, da violência como prática educativa e de histórico de uso de drogas na família de origem, especialmente entre os pais e irmãos dos usuários entrevistados. Nesse sentido, os dados deste estudo sugerem que o uso de drogas possa estar mais fortemente relacionado com o padrão de relacionamento familiar caracterizado pela presença desses fatores do que com a composição da mesma. Corroborando os achados deste estudo, Garcia, Pillon e Santos (2011) verificaram que o uso de drogas esteve mais relacionado à presença de violência e drogas no ambiente familiar do que às diferentes composições do núcleo familiar de origem.

A vitimização ocorrida na infância ou adolescência tem sido considerada um importante fator de risco para o uso de drogas na vida adulta (Shin, Miller, \& Teicher, 2013; Tondowski et al., 2011; Laranjeira et al., 2012; Huang et al.,
2011). Apesar de no Brasil existir o Estatuto da Criança e do Adolescente (ECA; Brasil, 1990), legislação específica que estabelece a proteção de crianças e adolescentes contra maus tratos, a prática de violência parece ser ainda comum e mais significativa entre usuários de drogas. Um estudo nacional que avaliou a presença de violência na infância entre usuários de crack verificou que esta era uma prática comum e aceita culturalmente como uma medida educativa. $\mathrm{O}$ mesmo estudo identificou que os sujeitos da pesquisa, muitas vezes, não definiram essas experiências como violentas (Dunlap, Golubbruce, \& Benoit, 2009). Nessa mesma direção, os usuários do presente estudo demonstraram perceber as experiências de vitimização muito mais como medida de correção/educação do que como violação de direito, apontando a necessidade da existência de ações preventivas ao uso de álcool ou outras drogas já na infância e que tenham como enfoque o desenvolvimento das habilidades educativas parentais e das habilidades sociais das crianças. Assim, reforça-se a necessidade de se trabalhar não apenas com o usuário, mas também com sua rede social e familiar, fortalecendo os vínculos com a família e com a comunidade.

Outro importante fator detectado nos relatos dos usuários foi o hábito de consumo abusivo de álcool ou outras drogas pelos membros da família durante a infância ou adolescência, corroborando a literatura (Botti, Costa, \& Henriques, 2011; Rudolph et al., 2011; Sanchez \& Nappo, 2002; Seleghim et al., 2011; Silva et al., 2010; Silveira \& Silva, 2013), sendo as drogas lícitas (tabaco e álcool), geralmente, as mais consumidas no ambiente familiar (Botti, Costa, \& Henriques, 2011; Sanchez \& Nappo, 2002). Ademais, os entrevistados revelaram o uso compartilhado dessas substâncias com os familiares, inclusive de crack, mostrando que alguns familiares propiciaram e facilitaram o uso de drogas. Dessa forma, entende-se que, quando um membro da família oferece e compartilha drogas com crianças ou adolescentes no ambiente familiar, institui-se que esse uso é permitido e aceito, ou seja, torna-o "menos proibido", favorecendo que esse indivíduo venha a ter problemas decorrentes do uso de substâncias.

Sabe-se que a família tem importante papel na transmissão de conhecimentos, valores, crenças e comportamentos, assim, os valores e atitudes aprendidos no convívio familiar são, muitas vezes, imitados e reproduzidos (Bernardy \& Oliveira, 2010). É importante ressaltar que crianças e adolescentes que vivem com pais que fazem uso abusivo de álcool ou outras drogas constituem um grupo de alto risco para a dependência de substâncias (Lam et al., 2007; Silva et 
al., 2010) quando comparados com filhos de não dependentes químicos, tanto em decorrência da própria facilidade de acesso à droga, presença constante de conflitos familiares, maior probabilidade de serem vítimas de violência física, sexual e de negligência, apontando a necessidade de se pensar em estratégias de prevenção específicas para esse grupo (Payá \& Figlie, 2010). Entretanto, é preciso também assinalar que não se pode atribuir uma relação causal entre esses fatores, ou seja, um filho de dependente de álcool ou outras drogas não necessariamente se tornará dependente de substâncias; seria simplificar a questão e desconsiderar os demais fatores envolvidos neste complexo fenômeno (Schenker \& Minayo, 2005).

O uso de álcool é culturalmente associado ao processo de socialização, comemoração e prazer. Assim, pode-se supor que muitos dos familiares dos entrevistados desconsideravam os efeitos nocivos do uso dessa substância e, por isso, o compartilhavam com os demais membros da família. Como uma possível consequência desta situação, foi detectado um início precoce do consumo de drogas entre a maioria dos entrevistados. Sabendo que a adolescência é um período de maior vulnerabilidade para o consumo de drogas e que, quanto mais precoce se dá esse início, maior será a tendência de se desenvolver uma dependência de substância em longo prazo (Moraes et al., 2010). Reforça-se, novamente, a importância da prevenção ao uso de drogas na infância e no início da adolescência, intervenções estas que lidem, entre outros aspectos, com a caracterização do ambiente familiar, tanto no que se refere aos aspectos culturais de uso de drogas quanto ao padrão de relacionamento entre seus membros, pois frequentemente também tem sido constatado que esse uso interfere na interação familiar de maneira negativa, ocasionando estresse, depressão, conflitos e violência (Moraes et al., 2010; Payá \& Figlie, 2010; Rotheram et al., 2015; Silva, 2011a; Vieira et al., 2014).

O presente estudo também verificou a presença de problemas, conflitos e violência no ambiente familiar decorrentes do uso de álcool ou outras drogas. A presença do uso de álcool nas situações de violência doméstica já é um tema estudado e constatado como frequente na literatura da área, sendo que o agressor se encontrava sob o efeito dessa substância em mais da metade dos casos deste tipo de violência (Fonseca, Golduróz, Tondowski, \& Noto, 2009; Rotheram et al., 2015; Silveira, Gebara, Noto, \& Lourenço, 2013; Vieira et al., 2014). Os dados do presente estudo sugerem que o uso de outras drogas, especialmente de crack, pode ser também um importante desencadeador de situações de conflito, de separações das figuras parentais e de violência no ambiente familiar em um momento em que a criança ou o adolescente estão em fase de desenvolvimento de seus modelos de comportamento.

\section{CONSIDERAÇÕES FINAIS}

Considerando a percepção dos usuários de crack sobre a sua família de origem, constatou-se a presença de diversos fatores no âmbito familiar que podem ter favorecido o início precoce do uso de drogas, assim como sua manutenção, tais como: a fragilidade dos vínculos familiares como resultado da presença de violência na infância ou adolescência tanto como uma maneira de se educar/punir como aquela decorrente do uso de álcool ou outras drogas pelos responsáveis; conflitos, perdas afetivas e separações das figuras parentais; histórico frequente de uso de álcool ou outras drogas na família de origem, assim como o uso compartilhado dessas substâncias entre os membros da família, inclusive, o de crack.

Os resultados revelam que a violência foi vivenciada pelos entrevistados por meio de maus tratos e abusos, além de presenciarem brigas e agressões entre os pais. Diante do exposto, destaca-se que a violência é um tema frequentemente presente nas relações familiares dos usuários de crack, sugerindo a necessidade de efetivação de políticas públicas que protejam as crianças e os adolescentes dos agravos dessa violência e do uso de drogas pelos pais. Assim, reforça-se a importância da implantação de programas que tenham como foco o desenvolvimento das habilidades educativas parentais para se prevenir a violência e outras consequências do uso de drogas entre os membros da família, assim como para se fortalecer os vínculos familiares daqueles que estejam mais vulneráveis a essa situação.

Além dessas constatações, destaca-se que este estudo objetivou a análise de um recorte das percepções dos usuários de crack acerca de suas relações familiares no momento anterior ao início do uso dessa substância. Diante destas considerações, sugere-se que estudos representativos desta população e longitudinais possam ser realizados para melhor entendimento das implicações das dinâmicas familiares no complexo fenômeno do uso de drogas em nossa sociedade, que vem sendo preocupação de educadores, profissionais da saúde e daqueles que constroem as políticas públicas no Brasil. Nesse sentido, este estudo poderá contribuir para a melhor compreensão da relação entre as dinâmicas familiares e o uso de crack, indicando a necessidade de se reforçar os cuidados aos familiares, os quais, muitas vezes, também enfrentam problemas no uso de substâncias e na implantação de ações educativas para o desenvolvimento de habilidades parentais na infância e adolescência como forma de prevenção aos problemas decorrentes do uso de drogas. 


\section{REFERÊNCIAS}

Albuquerque, B. S. (2010). Idade doida da pedra: Configurações históricas e antropológicas do crack na contemporaneidade. In L. F. Sapori \& R. Medeiros (Orgs.), Crack um desafio social (pp. 13-37). Belo Horizonte: Ed. PUC Minas.

Bastos, F. I., \& Bertoni, N. (Coords.). (2014). Pesquisa Nacional sobre o Uso de Crack: Quem são os usuários de crack elou similares do Brasil? Quantos são nas capitais brasileiras? Rio de Janeiro: Editora ICICT/FIOCRUZ.

Bernardy, C. C. F., \& Oliveira, M.L.F. (2010). O papel das relações familiares na iniciação ao uso de drogas e abuso por jovens institucionalizados. Revista da Escola de Enfermagem da Universidade São Paulo, 44(1), 11-17. doi: 10.1590/S008062342010000100002

Bordin, S., Figlie, N. B., \& Laranjeira, R. (2010). Cocaína e crack. In N. B. Figlie, S. Bordin, \& R. Laranjeira (Orgs.), Aconselhamento em dependência química (pp. 77-93). São Paulo: Editora Roca.

Botti, N. C. L., Costa, B. T., \& Henriques, A. P. F. (2011). Composição e dinâmica das famílias de usuários de crack. Cadernos Brasileiros de Saúde Mental, 3(7), 93-110. Recuperado de http://incubadora.periodicos.ufsc.br/index.php/ cbsm/article/ view/ 1907.

Brasil. (1990). Lei $n^{\circ} 8.069$, de 13 de julho de 1990. Institui o Estatuto da Criança e do Adolescente. Recuperado de http:// bd.camara.gov.br/ bd/bitstream/handle/bdcamara/785/ estatuto_crianca_adolescente_7ed.pdf

Brasil. (2010). Decreto $n^{\circ} 7.179$, de 20 de maio de 2010. Institui o Plano Integrado de Enfrentamento ao Crack e outras Drogas, cria o seu Comitê Gestor, e dá outras providências. Recuperado de http://www.planalto.gov.br/ccivil_03/Ato2007-2010/2010/ Decreto/D7179.htm

Carlini, E. A., Galduróz, J. C. F., Noto, A.R., \& Nappo, S. A. (2002). I levantamento domiciliar sobre o uso de drogas psicotrópicas no Brasil: Estudo envolvendo as 107 maiores cidades do país2001. São Paulo: Cromosete Gráfica e Editora Ltda.

Carlini, E. A., Galduróz, J. C. F., Silva, A. A. B., Noto, A. R., Fonseca, A. M., Carlini, C. M., \& Sanchez, Z. V. (2006). II Levantamento domiciliar sobre o uso de drogas psicotrópicas no Brasil: Estudo envolvendo as 108 maiores cidades do país2005. São Paulo: Páginas \& Letras.

Chaves, T. V., Sanchez, Z. M., Ribeiro, L. A., \& Nappo, S. A. (2011). Fissura por crack: Comportamento e estratégias de controle de usuários e ex-usuários. Revista de Saúde Pública, 45(6), 11681175. doi: 10.1590/S0034-89102011005000066

Cruz, M. S., Vargens, R. W., \& Ramôa, M. L. (2011). Crack: Uma abordagem multidisciplinar. In P. C. A. V. Duarte, \& A. G. Andrade (Orgs.), Integração de competências no desempenho da atividade judiciária com usuários e dependentes de drogas (pp. 127-149). Brasília: Ministério da Justiça, Secretaria Nacional de Políticas sobre Drogas.

Dunlap, E., Golubbruce, A., \& Benoit, J. (2009). Normalization of violence: Experiences of childhood abuse by inner-city crack users. Journal of Ethnicity in Substance Abuse, 8(1), 15-34. doi: 10.1080/15332640802683359

Fonseca, A. M., Galduróz, J. C. F., Tondowski, C. S., \& Noto, A. R. (2009). Padrões de violência domiciliar associado ao uso de álcool no Brasil. Revista de Saúde Pública, 43(5), 743-749. Recuperado de http://www.scielo.br/pdf/rsp/v43n5/24.pdf

Gabatz, R. I. B., Schmidt, A. L., Terra, M. G., Padoin, S. M. M., Silva A. A., \& Lacchini, A. J. B. (2013). Percepção dos usuários de crack em relação ao uso e tratamento. Revista Gaúcha Enfermagem, 34(1), 140-146. doi: http://dx.doi.org/10.1590/ S1983-14472013 000100018

Garcia, J. J., Pillon, S. C., \& Santos, M. A. (2011). Relações entre contexto familiar e uso de drogas em adolescentes de ensino médio. Revista Latino-Americana de Enfermagem, 19 (Número especial), 753-761. doi: 10.1590/S0104-11692011000700013

Hemovich, V., \& Crano, W. D. (2009). Family structure and adolescent drug use: An exploration of single-parent families. Substance Use and Misuse, 44(14), 2099-2113. doi: 10.3109/10826080902858375

Huang, S., Trapido, E., Fleming, L., Arheart, K., Crandall, L., French, M., \& Prado, G. (2011). The long-term effects of childhood maltreatment experiences on subsequent illicit drug use and drug-related problems in young adulthood. Addictive Behaviors, 36(1-2), 95-102. doi: 10.1016/j.addbeh.2010.09.001

Lam, W. K. K., Cance, J. D., Eke, A. N., Fishbein, D. H., \& Hawkins, S. R. (2007). Children of African-American mothers who use crack cocaine: Parenting influences on youth substance use. Journal of Pediatric Psychology, 32(8), 877-887. Recuperado de: http://www.ncbi.nlm.nih.gov/pubmed/17522115

Laranjeira, R., Madruga, C. S., Pinsky, I., Caetano, R., \& Mitsuhiro, S. S. (2012). II LENAD - II Levantamento de álcool e drogas. O uso de cocaina e crack no Brasil. Recuperado de http://inpad. org.br/wp-content/uploads/2013/03/LENAD_PressRelease_ Coca.pdf

Laranjeira, R., Sakiyama, H., Padin, M. F. R., Madruga, C. S., \& Mitsuhiro, S. (2013). LENAD-Levantamento nacional de família dos dependentes químicos. Recuperado de: http://inpad. org.br/_lenad-familia/

Minayo, M. C. S. (2010). O desafio do conhecimento: Pesquisa qualitativa em saúde (pp. 9-255). Rio de Janeiro: Hucitec.

Moraes, E., Chalem, E., \& Figlie, N. B. (2010). Abuso de álcool, tabaco e outras drogas na adolescência. In N.B. Figlie, S. Bordin, \& R. Laranjeira (Orgs.), Aconselhamento em dependência química (pp. 377-393). São Paulo: Editora Roca.

Moura, H. F., Benzano, D., Pechansky, F., \& Kessler, F. H. P. (2014). Crack/cocaine users show more family problems than other substance users. Clinics, 69(7), 497- 499. http://dx.doi. org/10.6061/clinics/2014(07)10

Nappo, A. S., Sanchez, Z. V. D. M., Oliveira, L. G., Santos, A. S., Coaradete, J., Jr., Pacca, J. C. B., \& Lacks, V. (2004). Comportamento de risco de mulheres usuárias de crack em relação às DST/Aids. São Paulo: Centro Brasileiro de Informações sobre Drogas Psicotrópicas.

Narvaez, J. C. M., Pechansky, F., Jansen, K., Pinheiro, R. T., Silva, R. A., Kapczinski, F., \& Magalhães, P. V. (2015). Quality of life, social functioning, family structure, and treatment history associated with crack cocaine use in youth from the general population. Revista Brasileira de Psiquiatria, 37(3), 211-218. doi:10.1590/1516-4446-2014-1494

Oliveira, L. G., \& Nappo, S. A. (2008). Caracterização da cultura de crack na cidade de São Paulo: Padrão de uso controlado. Revista de Saúde Pública, 42(4), 664-671. doi: 10.1590/S003489102008005000039

Payá, R., \& Figlie, N. B. (2010). Filhos de dependentes químicos. In N.B. Figlie, S. Bordin, \& R. Laranjeira (Orgs.), Aconselhamento em dependência química (pp. 362-376). São Paulo: Editora Roca.

Pettenon, M., Kessler, F. H., Guimarães, L. S., Pedroso, R. S., Hauck, S., \& Pechansky, F. (2014). Perceptions of parental bonding in freebase cocaine users versus non-illicit drug users. Indian Journal of Medical Research, 139(6), 835-840. Recuperado de http:/www.ncbi.nlm.nih.gov/pmc/articles/ PMC4164995/

Raupp, L., \& Adorno, R. C. F. (2011). Circuitos de uso de crack na região central da cidade de São Paulo (SP, Brasil). Ciências $e$ Saúde Coletiva, 16(5), 2613-2622. doi: 10.1590/S141381232011000500031

Ribeiro, L. A., Sanchez, Z. V. D. M, \& Nappo, S. A. (2010). 
Estratégias desenvolvidas por usuário de crack para lidar com os riscos decorrentes do consumo da droga. Jornal Brasileiro de Psiquiatria, 59(3), 210-218. doi: http://dx.doi.org/10.1590/ S0047-20852010000300007

Rodrigues, D. R. S. R, Conceição, M. I. G., \& Iunes, A. L. S. (2015). Representações sociais do crack na mídia. Psicologia: Teoria e Pesquisa, 31(2), 115-123. doi: http://dx.doi.org/10.1590/010237722015010994115123

Roehrs, H., Lenardt, M. H., \& Maftum, M. A. (2008). Práticas culturais familiares e o uso de drogas psicoativas pelos adolescentes: Reflexão teórica. Escola Anna Nery Revista de Enfermagem, 12(2), 353-357. Recuperado de http://www. scielo.br/pdf/ean/v12n2/v12n 2a24.pdf

Romanelli, G. (2003). Autoridade e poder na família. In M. C. B. Carvalho (Org.), A família contemporânea em debate (pp. 73-88). São Paulo: Educ/Cortez.

Rotheram-Borus, M. J., Tomlinson, M., Roux, I. L., \& Stein, J. A. (2015). Alcohol use, partner violence, and depression: A cluster randomized controlled trial among urban South African mothers over 3 years. American Journal of Preventive Medicine, 49(5), 715-725. doi: 10.1016/j.amepre.2015.05.004

Rudolph, A. E., Jone, K. C., Latikin, C., Crawford, N. D., \& Fuller, C. M. (2011). The association between parental risk behaviors during childhood and having high risk networks in adulthood. Drug and Alcohol Dependence, 118(2-3), 437-443. doi: 10.1016/j.drugalcdep.2011.05.003

Sanchez, Z. V. D. M, \& Nappo, S. A. (2002). Sequência de drogas consumidas por usuários de crack e fatores interferentes. Revista de Saúde Pública, 36(4), 420-430. doi: http://dx.doi. org/10.1590/S0034-89102002000400007.

Schaurich, D. R., Backes, D. S., Freitas, H. M. B., Zamberlan, C., Gelhen, M. H., \& Colomé, J.S. (2012). Conhecimentos produzidos acerca do crack: Uma incursão nas dissertações e teses brasileiras. Ciência e Saúde Coletiva, 17(5), 1247-1258. doi: 10.1590/S1413-81232012000500018

Schenker, M., \& Minayo, M. C. S. (2005). Fatores de risco e de proteção para o uso de drogas na adolescência. Ciência e Saúde Coletiva, 10(3), 707-717. doi: 10.1590/S141381232005000300027

Seleghim, M. R., Galera, S. A. F., \& Oliveira, M. L. F. (2014). Pesquisa com usuários de crack e seus familiares: Análise de uma vivência. Saúde \& Transformação Social, 5(1), 36-41. Recuperado de http://pepsic.bvsalud.org/scielo. php?script=sci_arttext\&pid=S2178-70852014000100007\&ln $\mathrm{g}=$ pt\&tlng $=$ pt.

Seleghim, M. R., \& Oliveira, M. L. F. (2013). Influência do ambiente familiar no consumo de crack em usuários. Acta Paulista de Enfermagem, 26(3), 263-268. doi: 10.1590/S010321002013000300010

Seleghim, M. R., Marangoni, S. R., Marcon, S. S., \& Oliveira, M. L. (2011). Vínculo familiar de usuários de crack atendidos em uma unidade de emergência psiquiátrica. Revista Latino-Americana de Enfermagem, 19(5), 1-8. doi: http://dx.doi.org/10.1590/ S0104-11692011000500014

Shin, A. H., Miller, D. P., \& Teicher, M. H. (2013). Exposure to childhood neglect and physical abuse and developmental trajectories of heavy episodic drinking from early adolescence into young adulthood. Drug Alcohol and Dependence, 127(13), 31-38. doi: 10.1016/j.drugalcdep.2012.06.005

Silva, E. A. (2011a). Mudanças no ciclo vital familiar na adolescência e abuso de drogas. In E. A. Silva \& D. De Micheli
(Orgs.), Adolescência uso e abuso de drogas: Uma visão integrativa (pp. 467-477). São Paulo: Ed. Unifesp.

Silva, E. A. (2011b). Prevenção ao uso de drogas: O papel da família. In E. A. Silva \& D. de Micheli (Orgs.), Adolescência uso e abuso de drogas: Uma visão integrativa (pp. 679-692). São Paulo: Ed. Unifesp.

Silva, E. A., \& De Micheli, D. (2011). Família: Uso e abuso de drogas entre o risco e a proteção. In P.C.A.V. Duarte \& A. G. Andrade (Orgs.), Integração de competências no desempenho da atividade judiciária com usuários e dependentes de drogas (pp. 213-229). Brasília: Ministério da Justiça, Secretaria Nacional de Políticas sobre Drogas.

Silva, L. H. P., Borba, L. O., Paes, M. R., Guimarães, A. N., Mantovani, M. F.,\& Maftum, M. A. (2010). Perfil dos dependentes químicos atendidos em uma unidade de reabilitação de um hospital psiquiátrico. Escola Anna Nery Revista de Enfermagem, 14(3), 583-590. doi: 10.1590/S141481452010000300021

Silveira, P. S., \& Silva, E. A. (2013). Família, sociedade e uso de drogas: Prevenção, inclusão social e tratamento familiar. In T. M. Ronzani (Org.), Ações integradas sobre drogas: Prevenção, abordagens e politicas públicas (pp. 207-222). Juiz de Fora: Ed. UFJF

Silveira, P. S., Gebara, C.; Noto, A. R., \& Lourenço, L. M. (2013). Violência e uso de drogas. In T. M. Ronzani (Org.), Ações integradas sobre drogas: Prevenção, abordagens e politicas públicas (pp. 223-247). Juiz de Fora: Ed. UFJF.

Souza, I. C. W., Amato, T. C., \& Sartes, L. M. A. (2013). Abordagem com adolescentes sobre o uso de álcool e outras drogas. In T.M. Ronzani (Org.), Ações integradas sobre drogas: Prevenção, abordagens e políticas públicas (pp.180-206). Juiz de Fora: Ed. UFJF.

Steiner, S., Schori, D., \& Gmel, G. (2014). Excessive alcohol consumption in young men: Is there an association with their earlier family situation?. Swiss Medical Weekly, 3(144), w14007.doi: 10.4414/smw.2014.14007

Szymanski, H. (2002). Viver em família como experiência de cuidado mútuo: Desafios de um mundo em mudança. Revista Serviço Social e Sociedade, 71(número especial), 9-25. São Paulo: Cortez.

Tondowski, C. S., Noto, A. R., Pimenta, M., Fonseca, A. M. (2011). Violência familiar, adolescência e uso de drogas. In E. A. Silva \& D. De Micheli (Orgs.), Adolescência uso e abuso de drogas: Uma visão integrativa (pp. 479-492). São Paulo: Ed. Unifesp.

Turato, E. R. (2005). Métodos qualitativos e quantitativos na área de saúde definições, diferenças e seus objetos de pesquisa. Revista Saúde Pública, 39(3), 507-514. doi: 10.1590/S003489102005000300025

Vieira, L. B., Cortes, L. F., Padoin, S. M. M., Souza, I. E. O., Paula, C. C., \& Terra, M.G. (2014). Abuso de álcool e drogas e violência contra as mulheres: Denúncias de vividos. Revista Brasileira Enfermagem, 67(3), 366-372. doi: http://dx.doi. org/10.5935/0034-7167.20140048.

United Nations Office on Drugs and Crime. (2010). World Drug Report. United Nations Publication, Sales No.E.10.XI.13, Recuperado de http://www.unodc.org/unodc/ en/data-andanalysis/WDR-2010.html

United Nations on Drug and Crime. (2014). World Drug Report. United Nations Publication, Sales No.E.14.XI.7, Recuperado de http://www.unodc.org/wdr2014 